\title{
The metaphoric motivation of the caused-motion construction: A case study of perception
}

\author{
NuRIa DEL CAMPo MARTÍNEZ* \\ University of La Rioja, Spain
}

Received: 15 June 2012 / Accepted: 27 September 2012

\begin{abstract}
This article addresses the caused-motion construction from the theoretical perspective of the Lexical Constructional Model (LCM). Within the LCM, the way in which lexical templates fuse with constructional templates is coerced by internal and external constraints. Internal constraints specify the conditions under which allow predicates to take part in a construction. External constraints take the form of high-level metaphoric and metonymic operations that affect lexical-constructional subsumption. This proposal makes use of the theoretical tools of the LCM with a view to exploring instantiations of the construction with verbs of perception. Apart from internal constraints, high-level metaphor will be found to play a prominent role in the construal of the examples under scrutiny. The study will suffice to point out that the semantics of the caused-motion construction needs to be understood with reference to the underlying metaphoric mappings.
\end{abstract}

KEYWORDS: caused-motion construction, Lexical Constructional Model, high-level metaphor, lexicalconstructional subsumption, verbs of perception.

\section{RESUMEN}

Este artículo examina la construcción de movimiento causado desde la perspectiva teórica del Modelo Léxico Construccional (MLC). En el MLC, la fusión de las estructuras léxicas con representaciones construccionales se regula por principios restrictores internos y externos. Los principios internos especifican la compatibilidad conceptual entre las estructuras léxicas y construccionales. Los principios externos regulan la posibilidad de que se produzcan procesos metafóricos y metonímicos en el proceso de subsunción. Haciendo uso de las herramientas analíticas proporcionadas por el MLC, esta propuesta explora el comportamiento de la construcción con verbos de percepción. El análisis de los ejemplos mostrará el papel fundamental de la metáfora de alto nivel, así como de otros factores de restricción internos. Este estudio nos permitirá concluir la necesidad de considerar el rol de la metáfora en la semántica de la construcción de movimiento causado.

PALABRAS CLAVE: construcción de movimiento causado, Modelo Léxico Construccional, metáfora de alto nivel, subsunción léxico-construccional, verbos de percepción.

*Address for correspondence: Nuria del Campo. University of La Rioja, Department of Modern Languages. Logroño, SPAIN. E-mail: nuria.delcampo@hotmail.es 


\section{INTRODUCTION}

This article examines the metaphoric representation of the caused-motion construction. The caused-motion construction has been central to many recent studies on argument structure within Cognitive Grammar (Goldberg, 1995, 2006). ${ }^{1}$ The construction describes a change of location of an entity caused by the action denoted by the verb (e.g. The child kicked the ball into the garden). By definition, all verbs of motion should be expected to take part in the caused-motion construction, in much the same way as verbs which are not associated to motion should represent marginal uses. However, one does not need to search far to see that this is not the case. Certain verbs of motion cannot be used in many instances of the construction (e.g. hurry, speed), while many others unrelated to motion work perfectly (e.g. frighten, laugh). Current theories on the syntax-semantics interface develop incomplete views on why this kind of incompatibilities occurs. Projectionist approaches (Dik, 1989, 1997; Van Valin and LaPolla, 1997; Van Valin, 2005) hold that the syntactic structure is projected from the lexical representation of the verb. Nevertheless, as has been made obvious in Construction Grammar circles (Kay and Fillmore, 1999; Goldberg, 1995, 2006; Croft, 2001), argument structure is insufficient to explain the occurrence of certain predicates (e.g. the resultative sense of see in I would like to see the work finished soon). Constructions may contribute arguments to yield the semantic interpretation of a particular expression, creating constraints on the way predicates fuse with the syntactic structure. But constructionist views have not specified what it is that licenses or blocks the integration of predicates into syntactic structures.

The Lexical Constructional Model (LCM) (Ruiz de Mendoza \& Mairal, 2008, 2011; Mairal \& Ruiz de Mendoza, 2009) was conceived to account for the understanding of the relationship between lexical and syntactic meaning by merging into one unified approach theoretical assumptions from functional projectionist theories and constructional models. ${ }^{2}$ In dealing with argument structure, the LCM organizes lexical items into predicate classes associated with a semantic domain by making use of a decompositional system that captures syntactically relevant semantic meaning. Drawing on Role and Reference Grammar (RRG) (Van Valin \& LaPolla, 1997; Van Valin, 2005), the LCM has developed a decompositional system based on lexical functions and primitives which reveals the properties that lexical items share, thereby allowing formulating generalizations about to the ascription of predicates for a given construction. Further, the LCM has put forward a set of internal and external constraints which explain the conceptual compatibility between constructions and lexical items, as well as many other grammatical phenomena, such as constructional alternations and cases of categorial and subcategorial conversion. Internal constraints state the conditions under which lexical structures may participate in constructional configurations. External constraints refer to cognitive operations that affect subsumption processes either permitting or disallowing them (see Ruiz de Mendoza, 2011, for details).

(C) Servicio de Publicaciones. Universidad de Murcia. All rights reserved. IJES, vol. 13 (1), 2013, pp. 89-110 Print ISSN: 1578-7044; Online ISSN: 1989-6131 
This article shows how the constraints posited by the LCM to account for lexicalconstructional subsumption are applied to the domain of motion, paying special attention to the role of metaphor. Within the LCM, both metaphor and metonymy are regarded as external constraining factors licensing the adaptation of predicates to constructional meaning. For example, the use of laugh in the caused motion construction (e.g. The audience laughed the actor off the stage) would be motivated by a metaphorical operation whereby an experiential action is conceptualized as an effectual one. Such a metaphor imposes constraints on lexicalconstructional subsumption by licensing the subcategorial conversion of laugh at into laugh (see Ruiz de Mendoza and Mairal, 2007). ${ }^{3}$ In turn, the INSTRUMENT FOR ACTION metonymy would license categorial conversion of the noun hammer into a predicate in $\mathrm{He}$ hammered the nail into the wall (Kövecses and Radden, 1998). Taking sides with the view of metaphor and metonymy as constraining factors on lexical-constructional subsumption, this article analyzes the semantic basis of instantiations of the caused-motion construction with verbs of perception. This analysis will account for the metaphoric operations licensing the compatibility between perception verbs and the caused-motion construction. The discussion will proceed as follows: first I will focus on defining the grammatical pattern of the construction under scrutiny as well as on characterizing the types of constraints that regulate the way in which predicates fuse with constructions, with an emphasis on metaphoric and metonymic operations. To do so, I will revisit Goldberg's semantic constraints on the use of the construction and the refinements proposed within the LCM. Then I will examine the metaphorical grounding of a number of instances of the caused-motion construction by drawing evidence from the LCM approach, and finally I will summarize the resulting main points by way of conclusion.

\section{THE CAUSED-MOTION CONSTRUCTION}

Goldberg's (1995: 152ff) research on the caused-motion construction is probably the most extensive in Construction Grammar circles. Since we will focus on the argument structure of the construction, it is of vital importance to understand the Goldbergian approach. For Goldberg, argument structure constructions carry meaning independently of the predicates which they may take. Goldberg posits five subclasses of abstract constructions that provide core grammar characterizations: ditransitive (e.g. Pat faxed Bill the letter), caused-motion (e.g. They sprayed paint onto the wall), resultative (e.g. She kissed him unconscious), intransitive motion (e.g. The fly buzzed into the room) and conative (e.g. Sam kicked at Bill). ${ }^{4}$ Constructions designate dynamic scenes that are basic to human experience such as transfer, change of location and change of state (Goldberg, 1995; Fillmore, 1968; Langacker, 1991). The meaning of the verbs which take part in the constructions is understood against the background of these semantic frames. From this perspective, constructions do not possess a 
unique meaning but rather interact with the meaning of other constructions forming a network of relationships. The prototypical sense of the caused-motion construction is, for instance, the caused-movement of an entity to a designated place (e.g. He pushed the box into the room).

The basic semantics of the construction involve a causer argument which causes a theme argument to move along a path designated by a directional prepositional phrase ( $\mathrm{X}$ CAUSES Y TO MOVE Z). This interpretation involves manipulative causation and actual movement and is thus argued to be the central sense of the construction. Various extensions from this basic sense can occur in relation to the differences in the meanings of the predicates which take part in the construction. These senses cover cases when the verb does not strictly entail motion (e.g. Tom invited Sally into the hall), denotes the removal of a barrier (e.g. The guards allowed the prisoner out of the cell), causes the patient to stay in a location (e.g. The mother locked the child into the back room) and implies continuous assistance to move (e.g. The nurse walked the man into an ambulance). These various senses of the construction interact regulated by a number of conceptual links which capture the way in which the information between distinct types of configurations is shared. Goldberg distinguished four kinds of links (Goldberg, 1995: 73ff). Polysemy links, in the first place, capture the relation between any particular sense of a construction and the extensions from this sense. In the case of the caused-motion construction, polysemy is illustrated by the verbs in Pat pushed Tom into the room and Pat ordered John into the room. ${ }^{5}$ The second kind of links are subpart links, which are posited when a construction is a subpart of another. For example, the intransitive motion construction (e.g. The dog walked down the street) is a subpart of the caused-motion construction, which adds a causal element (e.g. John walked the dog down the street). Instance links, thirdly, occur when a construction is an instance of another (e.g. the sense of drive in the resultative construction, constraining the argument to mean 'crazy'). The fourth kind of links, and the most interesting for our purposes here, are metaphorical extension links, which relate two constructions by a metaphorical mapping. This is the case of the relationship between the resultative construction and the caused-motion construction are connected by a metaphor which structures states in terms of locations, allowing us to conceptualize caused change as caused motion. In line with Goldberg's metaphorical extension links, the LCM regards metaphor and metonymy licensing factors for lexicalconstructional subsumption processes.

The positing of conceptual links seeks to capture the semantic and syntactic relations among constructions, which is one of the major concerns in Goldberg's work. It is also crucial the relationship between constructions and predicates, which is accounted for in the form of semantic constraints that specify the conditions that constructions impose on lexical meaning. Let us consider the five generalizations that Goldberg (1995: 164ff) presents in relation to the semantic constraints that affect the use of the caused-motion construction. It is specified, in the first place, that no cognitive decision mediates between the causing event and the entailed 
motion (e.g. He frightened/*persuaded the mouse out of its hiding place). It is further specified that the theme argument is presumed to move into the specified location (e.g. John asked/*pleaded Sam into the room) and the path motion must be determined by the causal force (e.g. He shoved/*He nudged the cart down the incline). It is also stated that the path of motion cannot be specified if the verb denotes an effect other than motion (e.g. He hit/*struck the ball across the field). These constraints have shown largely problematic, as they are unable to cover many instantiations of the construction. In recent work, Luzondo (2007) has provided a number of examples containing contact-by impact verbs which specify the path of motion (e.g. Pat shot Sam across the room), contrary to Goldberg's claims. In much the same way, Peña (2009) has shown that the application of cognitive operations like metaphor and metonymy allows covering uses of the caused-motion construction with verbs where the expression of motion is figurative. The reason why Goldberg's constraints do not explain the behavioral patterns of the construction is because they lie on the nature of the predicates used, which is insufficient to account for the application of the construction in every single context. As has been shown within the LCM, the use of verbs in the caused-motion construction is not a matter the semantics of the predicate, but rather of the nature of the predicate along with different cognitive constraints which either license or blocks out motion. Next section shows the constraints posited by LCM as regulating lexical-constructional subsumption.

\section{SEMANTIC CONSTRAINTS WITHIN THE LEXICAL CONSTRUCTIONAL MODEL}

\subsection{Brief outline of the Lexical Constructional Model}

The LCM integrates assumptions from functional projectionist theories (Van Valin and La Polla, 1997; Van Valin, 2005), the Goldbergian Construction Grammar and other cognitive models of language (Lakoff 1987, 1993; Lakoff and Johnson, 1999). The LCM is thus a constructionist model of language where, unlike in most constructionist accounts, lexical structure plays an important role. In the LCM, a construction is defined as a pairing of form and meaning where form affords access to meaning and meaning is realized by form to the extent that such processes have become entrenched in the speaker's mind and are generally recognized by the speech community to be stably associated. For a construction to be such it needs to be potentially replicable by other speakers with minimal variation in its form and meaning (Ruiz de Mendoza and Galera, 2012). This definition overcomes one of the problems inherent to the current understanding of a construction as an entrenched (i.e. frequent) formmeaning/function pairing (cf. Langacker, 2005; Goldberg, 2006). This is the introduction of the notion of frequency in the definition. Since it is difficult to find adequate criteria to determine when a form-meaning pairing is sufficiently frequent, the LCM has substituted the 
notion of replicability of such pairings by competent native speakers of the language. This means that even if a form-meaning connection is not very frequent in a corpus, if it has been produced by at least one competent speaker, if it is understood (i.e. accepted as meaningful) by other speakers and it is not rejected as odd or inadequate (i.e. as doing violence to the principles of language use), it can be given constructional status.

The LCM is focused on the study of the relationship between syntax and all aspects of meaning construction, positing four descriptive levels, which deal with argument structure, implicated meaning, illocution and discourse phenomena. Level 1 consists of elements of syntactically relevant semantic representation based on the interaction between lexical and constructional templates. Lexical templates are non-generic semantic representations of the syntactically relevant content of a predicate which captures lexical structure. Constructional templates consist of generic or abstract semantic representations of syntactically relevant meaning elements that derive from lower-level representations and are based on Goldberg's (1995, 2006) construction types (e.g. ditransitive, caused motion, resultative, intransitive motion and conative). Lexical and constructional templates interact at all levels of linguistic description and they partially resemble each other in predictable ways. Level 2, or implicational module, addresses inferencing on the basis of low-level situational cognitive models. Level 3, or illocutionary module, deals with illocutionary (i.e. high-level inferencing). Finally, level 4 accounts for discourse aspects, with particular emphasis on cohesion and coherence phenomena. Each of the levels is either subsumed into a higher configuration or acts as a cue for the activation of relevant conceptual structure that yields an implicit meaning derivation regulated by a number of cognitive and pragmatic constraints. Two operations regulate the meaning derivation process: subsumption and conceptual cueing. The former is a meaning production mechanism by which lower-level structures are absorbed into higher-level configurations. Subsumption is internally and externally constrained. The latter is a form of guided interpretation on the basis of linguistic and constructional clues. Cued inferential activity takes place at the four constructional levels as an alternative to subsumption. At the level of core grammar (cf. Mairal and Ruiz de Mendoza, 2009: 194), it takes the form of inferences obtained by making contextual adjustments to the meaning of predicates. At levels 2, 3 and 4 cued inferencing accounts for meaning implications obtained on the basis of conceptual connections among propositions (in discourse) or on metonymic access to high-level (for illocution) and low-level (for traditional implicature) situational models.

The LCM approach is based on two methodological assumptions. The first relates to the idea that all levels of linguistic description make use of the same, or at least comparable, cognitive processes. This assumption is termed the equipollence hypothesis, which has enabled the model to achieve a certain degree of consistency and greater simplicity in the study of meaning construction (Mairal and Ruiz de Mendoza, 2009). Through the application 
of the hypothesis, the LCM has been able to identify metaphor and metonymy at non-lexical levels of linguistic description and explanation, and to postulate metaphorical and metonymic operations as constraining factors on lexical-constructional fusion. The second assumption has to do with the existence of a continuum between linguistic categories. Both assumptions aim to achieve the adequacy criteria proposed by Dik (1989) for his theory of Functional Grammar. Figure 1 below reproduces the various aspects of the overall architecture of the LCM (Ruiz de Mendoza and Gonzálvez, 2011). It portrays all constructional levels (i.e. argument structure, implicational, illocutionary and discourse), as well as the cognitive

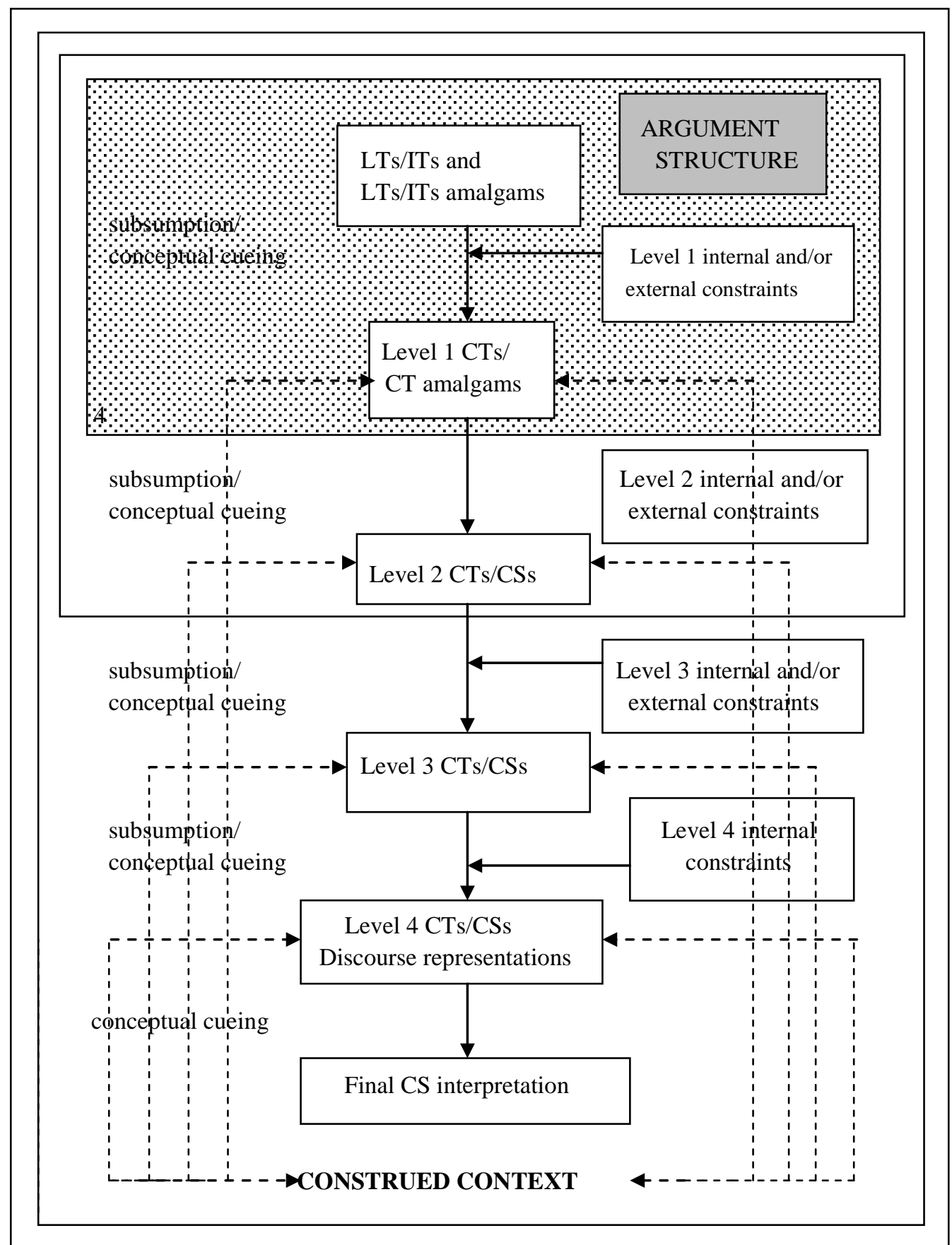

Figure 1. The overall architecture of the LCM

(c) Servicio de Publicaciones. Universidad de Murcia. All rights reserved. IJES, vol. 13 (1), 2013, pp. 89-110 Print ISSN: 1578-7044; Online ISSN: 1989-6131 
processes licensing the incorporation of lower-level configurations into higher-order ones (i.e. conceptual cueing and subsumption).

This article is only concerned with level 1, specifically with the fusion of lexical templates into constructional patterns. ${ }^{6}$ Lexical-constructional subsumption processes are internally and externally constrained on the basis of cognitive mechanisms. Internal constraints refer to the semantic units encoded in a lexical or constructional template, while external constraints make reference to conceptual mechanisms like high-level metaphoric and metonymic operations. It is upon this last group of constrains that we will focus our attention here.

\subsection{Constraints on lexical-constructional subsumption}

The type of constraints admitted to exist as affecting lexical-constructional subsumption are internal and external. Internal constrains generally specify the conditions under which lexical templates may modify their internal configuration for a constructional template to be realized by a lexical item. They take the form of licensing or blocking factors depending on lexical class ascription, lexical-constructional compatibility and variable predicate conditioning. The Lexical-Constructional Model postulates the following internal constraints: full matching, internal variable fusion, lexical class constraint, lexical blocking and predicate-argument conditioning. Full matching specifies that the lexical item needs to fulfill all constructional requirements. For instance, drink, which is a transitive verb (e.g. Let's drink some whiskey on ice) may occur in the intransitive form (e.g. I just want to drink and unwind), being forced to eliminate its second argument in order to take part in the construction. Internal variable fusion states that the subevents specified by lexical and constructional templates need to match. This constraint specifies, for example, that the motion subevent of the conative construction licenses the incorporation of verbal predicates that exhibit the same quality (e.g. John hit at the wall with a stick) and blocks out those which do not contain a motion subevent (e.g. *John touched at the wall). Lexical class constraint accounts for the restrictions that verbal class ascription place on lexical-constructional subsumption. This constraint explains why the verb break can occur in the inchoative construction (e.g. The arrow broke easily), while the verb destroy, which shares part of its conceptual structure with break, cannot (e.g. *The house destroyed). ${ }^{7}$ Lexical blocking covers cases in which one component of the lexical template rules out the fusion with a given construction, when such a component is a suppletive form. This constraint blocks out the use of kill in the inchoative construction because the form die is coded in the linguistic system with the same meaning. Predicate argument conditioning accounts for the limitations on the way constructional variables are realized. Sometimes lexical templates can place restrictions on the kind of instantiating element that we can have for a constructional argument. Consider the structure of the caused-motion construction, 
which takes the (simplified) form of $X$-pred-Y(=NP)-Z(=PP). In theory, the constructional template can take any verb participant to instantiate the Y element, which can be either human (e.g. Peter kicked John out of the room) or non-human (e.g. The dog chased the cat out of the house). However, once the predicate and PP slots have been filled in, this choice constrains the kind of $\mathrm{Y}$ element which can be used. In constructions where the Y element has been realized by a human verb role (e.g. Tom helped her father into the car), a non-human element (e.g. *Tom helped the chair into the car) is not possible.

These constraints act on subsumption processes by specifying conditions that make reference to the internal semantic makeup of lexical and constructional templates. We shall now devote our attention to other types of constraint put forward by the LCM that act on lexical-constructional subsumption by specifying conditions external to the process. In the LCM, high-level metaphor and metonymy are considered two prominent cases of external constraints on the lexical-constructional fusion process. Metaphors and metonymies of this kind, which have not been recognized in more traditional views, have been labelled high-level due to their impact on grammatical organization. ${ }^{8}$ High-level metaphor and metonymy have been found to underlie disparate phenomena such as conversion processes as well as some constructional alternations (Ruiz de Mendoza and Pérez, 2001; Ruiz de Mendoza and Peña, 2008; Peña and Ruiz de Mendoza, 2009). For example, the countable noun America is made uncountable in There is a lot of America in what she does motivated by the metonymy AN OBJECT FOR ONE OF ITS PROPERTIES. Similarly, the metonymy AGENT FOR ACTION underlies the categorial conversion of the noun author into a verb in This play was authored by Shakespeare. Another case in point is the deviant use of verbs like dust and vacuum in I dusted the room and vacuumed the carpet, where the metonymy OBJECT FOR ACTION is at work. Grammatical constructions associated with action predicates can also make use of stative predicates like be, as the imperative form (e.g. Be quiet) or the why not pattern (e.g. Why not be sincere?) (see Panther and Thornburg, 2000). Likewise, metaphor has been detected in grammatical alternations and conversion processes. An example is He talked me into it, where the predicate talk, which designates an activity, is treated as if it were an effectual action (i.e. an action that has a direct physical impact on the object causing it to change location). Another metaphoric mapping is illustrated by She collapsed and laughed herself out of silence, where the intransitive predicate laugh is transitivized to make it compatible with the caused-motion structure underlying the resultative construction. Such conversion is guided by a high-level metaphor that conceives of experiential actions in terms of effectual actions (Ruiz de Mendoza and Mairal, 2008). This metaphor opens the door to a wide range of conversions of predicates denoting experiential actions into the caused-motion construction by allowing us to see features of these verbs as if they were features of a different kind that can be adapted to constructional requirements. 
The positing of internal and external constraints as licensing factors in lexicalconstructional subsumption has two important advantages. In the first place, accounting for fusion processes in terms of constraints referring to the internal semantic makeup of verbal predicates allows explaining why and how they can be incorporated into any grammatical construction. Secondly, the apparatus of external constraints provides us with cognitive operations on coercion that achieve a satisfactory understanding of the fusion mechanisms. Furthermore, postulating metaphor and metonymy as underlying subsumption processes permits to account for relevant meaning implications that derive from coercion and whose communicative impact may otherwise be lost from linguistic description. Let us now concentrate on the role of metaphor in the coercion of verbs of perception in the causedmotion construction, as well as on the way metaphorization processes allows us to account for the constructional meaning of verbs related and unrelated to motion, as will be shown in section 4 below.

\section{THE CAUSED-MOTION CONSTRUCTION OF PERCEPTION}

Taking the sets of constraints that license the fusion of predicates into argument structure constructions as a point of departure, I discuss multiple cases of realization of the causedmotion construction and identify the constraints that affect the use of verbs of perception into the construction. ${ }^{9}$ The present discussion will be focused on how perception verbs are coerced onto metaphorical abstract domains to participate in the caused-motion construction. Together with other internal constraints referring the semantic compatibility between the internal variables of the construction and the predicates used, metaphor will be shown as having a prominent role in the fusion of perception verbs into the construction.

\subsection{Tactile perception}

The caused-motion construction requires a verbal predicate that expresses an effectual action. In order to be subsumed into this pattern, tactile activities require to be mapped onto a metaphor that allows us to see perceptual actions as if they were effectual actions with a physical impact on the object. The metaphor is nonetheless different depending on the result predicate: when the result predicate refers to a place (i.e. room, cave), tactile perception is mapped onto an effectual action, whereas when it makes reference to figurative motion (i.e. fear, silence), the activity is mapped onto an effectual accomplishment (see Baicchi, 2012, for details and similar examples):

(1) No harm could have touched me out of my fear. ${ }^{10}$

(2) It was a naive baby love story, but it touched me into tears. ${ }^{11}$ 
Examples (1) and (2) illustrate cases of the construction where the expression of motion is figurative. There is an instigated change of state that is expressed through a caused-motion pattern where the object is followed by a predicate specifying the outcome of the state change. The verb touch can participate in the construction because it shares relevant elements of structure, that is, an action that causes a change of state.

(3) The day came when his mother also nudged him out of the safety of her nest. ${ }^{12}$

In (3), the result predicate refers to an actual place, which allows the construction to express real motion. The predicate nudge is naturally transitive and does not need any kind of adjustment to take part in the construction.

(4) His beautiful accent caressed her into silence. ${ }^{13}$

(5) The smell of the soil and a gentle breeze soon caressed him into sleep. ${ }^{14}$

In (4) and (5), the caused-motion construction is again used figuratively to express a change of state. With regard to change of state situations, Goldberg (1995) claims that motion is implied in the action denoted by the verb. From the perspective of the LCM, this is due to a metaphorical mapping that structures states in terms of locations.

(6) The guard man handled him out of the room, still bleeding profusely. ${ }^{15}$

(7) They manhandled the piano down the stairs. ${ }^{16}$

The two predicates used in (6) and (7) are action verbs that meet the syntactic requirements of the caused-motion construction. Even though they do not denote physical impact, the metaphor enables us to understand that the action is carried out in such a way that the causee undergoes a change of location.

(7) The door opened and palmed me out onto a pavement. ${ }^{17}$

(8) He murmured at his white horse and stroked him out of the cave. ${ }^{18}$

Examples (7) and (8) feature transitive verbs that are compatible with the prerequisites imposed by the construction. In the two cases, the result predicate makes reference to a place, rendering the expression of motion explicit.

(9) My wife kicked me out of the house. ${ }^{19}$

(10) They located the night watchman and kicked him into unconsciousness. ${ }^{20}$ 
The verb kick is a contact-by-impact predicate (Levin, 1993). Predicates belonging to this class do not generally have a caused-motion meaning, although they can participate in the construction through coercion. In application of predicate-argument conditioning, we can understand the object to receive the impact denoted by the verb, and by being unable to absorb the impact, to be forced to move along a designated path (see Luzondo, 2007, for a study of the behavior of contact-by-impact verbs in the caused-motion construction).

(11) My dogs licked him out of his stupor yesterday. ${ }^{21}$

In (11), the predicate lick, which involves physical contact, is allowed to occur in the caused-motion construction by reinterpreting it as a causative accomplishment predicate that causes the object to move from one location to another. This reinterpretation is licensed by the effectual action metaphor.

(12) He tickled me into a corner. ${ }^{22}$

(13) I tickled her out of bed and we both scrambled downstairs famished. ${ }^{23}$

The predicate tickle can take part in the construction due to the metaphorical operation that conceives the activity as having an effect on the object.

(14) The door bell stung me out of my day dreams. ${ }^{24}$

(15) He pushed that snake hard and pinched me out of the center tower. ${ }^{25}$

Both predicates in (14) and (15) are transitive and made compatible with the causedmotion pattern thanks to the effectual action metaphor that treats them as effectual actions. The metaphor is, however, different in each case, since the destination element of the motion is a psychological state in (14) and a physical space in (15).

\subsection{Visual perception}

It has already been explained that the use of perception predicates in the caused-motion construction is possible to the extent that their meaning can be seen as if they were effectual actions through a metaphorical operation. This is also the case for visual perception verbs, which are conceptualized as having an effect on the object that causes the object to move.

(16) Today saw me into the office for meetings and brainstorming. ${ }^{26}$

The use of the predicate saw with a caused-motion sense in (16) above is grounded on the metaphor AN ACTIVITY IS AN EFFECTUAL ACTION. The example is itself based on 
the metaphor EXISTENCE IS PERCEPTION, which licenses the use of the time complement (i.e. today) as the subject of the caused-motion construction and acts on the source element of the metaphorical correlation between perception and effectual action, forming a metaphorical chain (see Ruiz de Mendoza, 2007, for details on this form of conceptual interaction).

(17) I will never forget the look on his face when he looked me out of that lab. ${ }^{27}$

(18) We looked him into the bathroom until he had a shower. ${ }^{28}$

The effectual action metaphor explains the non-conventional transitive use of look in (17) and (18). From this point of view, the verb undergoes a subcategorial conversion from a purely intransitive predicate to a transitive version that conveys an action that has an impact on the effectee. In other words, the iterative action of looking ends up working as if causing the patient to be metaphorically affected in such a way that the agent's look causes the patient to act. The transitive use of look is also accounted for by the internal constraint predicateargument conditioning, according to which predicates need to cooperate with the arguments of the construction.

(19) He watched her out of the room. ${ }^{29}$

The verb watch is transitive and therefore adapts to the syntactic requirements of the construction, although its semantics rely on a metaphorical operation with an effectual action in the source in order to express caused-motion.

(20) At her uncle's table she defied me, and imagined she had gazed me into cowardice. ${ }^{30}$

(21) She practically gazed him into the ladies room. ${ }^{31}$

In keeping with the predicate-argument conditioning constraint, the meaning of the predicate needs to adjust to the overall meaning of the structure in which it is incorporated. In (20) and (21), the verb gaze stops being an intransitive predicate and becomes a transitive predicate through a metaphorical reinterpretation to be compatible with the caused-motion construction.

(22) The captain blew through his nose loudly and stared him out of the room. ${ }^{32}$

(23) He stared me into an assenting nod. ${ }^{33}$

In much the same way as in the previous cases, the effectual action metaphor licenses the transitivization of stare to take part in the caused-motion construction. Evidently, the 
predicate-argument conditioning adds to the set of external constraints provided by the metaphor, licensing the incorporation of the verb into the construction.

(24) My curiosity has peeked me into trouble on more than one occasion. ${ }^{34}$

Once inserted into the construction, the intransitive verb peek is coerced into changing its argument configuration motivated by the effectual action metaphor, which introduces the idea of attempted motion.

\subsection{Auditory perception}

Auditory perception predicates are allowed to take part in the caused-motion construction thanks to an effectual action metaphor that structures auditory activity in terms of effectual action. As it was the case before, the metaphorical mapping changes depending on the result predicate. When the result predicate describes a concrete place, the expression is based on the metaphor AUDITION IS EFFECTUAL ACTION; when the result predicate makes reference to a mental state, the expression is based on the metaphor AUDITION IS EFFECTUAL ACCOMPLISHMENT.

(25) Margot listened me into greater clarity. ${ }^{35}$

(26) My children listened me into being a storyteller. ${ }^{36}$

The effectual action metaphor allows the subcategorial conversion of listen into a transitive verb in order to participate in the caused-motion construction. The destination of motion is figurative in both (25) and (26). Example (26) illustrates a case of the into-gerund construction, which has been included into the caused-motion construction functioning as an argument of the main verb (see Faber and Mairal, 1999: 124). In this particular case, the intogerund construction expresses the idea of motion motivated by a metaphor that conceives concrete actions in terms of locations (see Baicchi, 2012).

(27) She smiled and she heard him into her shoulder. ${ }^{37}$

(28) They heard him into the hall. ${ }^{38}$

Owing to the predicate-argument conditioning constraint, the construction contributes two arguments in order for the intransitive use of hear to occur. The high-level metaphor is an external constraint that underlies the subcategorial conversion of the predicate by means of a conceptualization of the hearing activity as an effectual accomplishment. 


\subsection{Olfactory perception}

The use of predicates related to olfactory perception is licensed by a metaphoric mapping that structures the activity of smelling as effectual actions involving physical motion, in much the same way as other perception predicates.

(29) The family dog smelled her out of her hiding place. ${ }^{39}$

The effectual action metaphor motivates the caused-motion sense of smell in (29), allowing us to see the activity of smelling as forcing the patient to move out from her hiding place. The verb smell is purely intransitive and therefore able to participate into the construction without undergoing any conversion. This partially contrasts with the example below:

(30) Hide week-old kippers under his floorboards and stink him out of your life. ${ }^{40}$

The predicate stink is intransitive and is coerced to add one argument in order to take part in the construction. The process is coerced both externally by the metaphor that conflates stinking and caused motion and internally by the predicate-argument condition, which gives the second argument to the verb.

(31) It must have been her perfume; it whiffed him into temporary insanity. ${ }^{41}$

(32) Grass was poison-sprayed which whiffed me into headache. ${ }^{42}$

A similar situation occurs in (31) and (32) above; with the difference that the result predicate designates a psychological state and the metaphor maps whiffed onto effectual accomplishment. Note, incidentally, the result predicate is negative in both utterances. This is so because our knowledge related to the whiffing scenario contains the idea that strong odors may make us feel sick.

\subsection{Gustatory perception}

Predicates related to gustatory perception are also licensed to take part in the caused-motion construction thanks to a metaphorical mapping with an effectual action in the source domain that conceptualizes gustatory activities like tasting as causing physical motion.

(33) Everyone tasted Halloween ale out of the bottle. ${ }^{43}$

(34) I tasted the wine out of the barrel. ${ }^{44}$ 
It is the effectual action metaphor that allows us to see tasting drinks as moving them out of their container. The verb taste is purely transitive and perfectly adapted to the syntactic component of the caused-motion construction.

(35) The criminals were forced to retreat as the dog bit them out of the house. ${ }^{45}$

(36) The shark bit the diver out of the cage. ${ }^{46}$

The metaphorical mapping forces the subcategorial conversion of the intransitive bite into transitive to take part in the caused-motion construction in a process which is regulated by the predicate-argument conditioning constraint. We have a similar situation in (37) and (38) below:

(37) The goose lowered his beak and nibbled the grass out of her palm. ${ }^{47}$

(38) An older woman came up to me and chewed me into tears. ${ }^{48}$

The effectual action metaphor licenses the transitivization of nibble and chew to be subsumed into the construction. In (37), the result predicate refers to a physical place, while it denotes a psychological state in (38). Differently from other perception verbs, the motion that is expressed by gustatory activity rarely has a mental state as the goal, probably due to the difficulty of seeing tasting as having a psychological impact on a patient.

\section{THE SUBSUMPTION OF PERCEPTION PREDICATES INTO THE CAUSED- MOTION CONSTRUCTION}

A metaphor is generally defined as a set of correspondences across two conceptual domains, one of which, called the source, allows us to understand the other, called the target. Within the LCM, metaphor constrains subsumption processes by licensing or blocking out the incorporation of lexical items into argument structure constructions. The integration of perception verbs in the caused-motion construction is licensed by a high-level metaphor that maps perception onto effectual action. This metaphor allows us to see perceptual activities as if they were effectual. The target is a perceptual domain that features a goal element that is affected by a causal event. Consider, for example, the metaphoric constraints that license the integration of stare into the caused motion construction in The captain blew through his nose loudly and stared him out of the room:

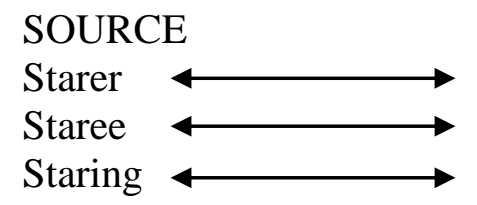

TARGET

Causer of motion

Moving patient

Destination of motion 
A simplified representation of the lexical-constructional subsumption of stare into the caused-motion construction as conceived within the LCM is provided in figure 2 below:

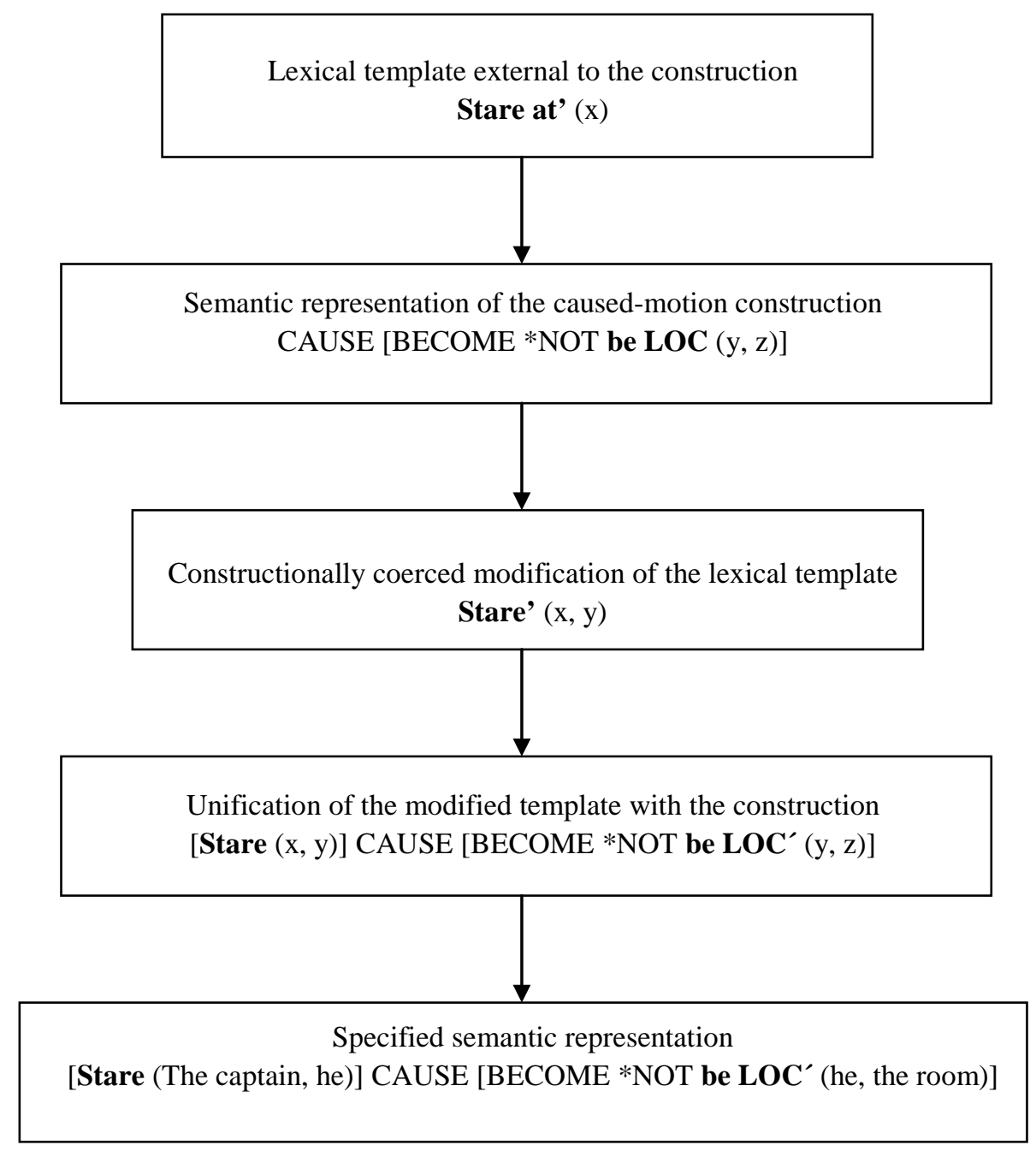

Figure 2. Lexical-constructional subsumption of The captain blew through his nose loudly and stared him out of the room with the caused-motion construction

For the construction to capture the fusion of the verb, three compulsory elements need to be present: (i) an effector; (ii) an affected object, and (iii) the reaction of the object as a result of the motion caused. The effectors and effectees correlate for perception actors and goals for the verbal predicate to preserve the meaning implications when built into the construction. The action expressed by the predicate conflates with the force applied to the object, and is thus seen as if it had a direct physical effect. ${ }^{49}$ This metaphor imposes constraints on lexical-constructional subsumption by permitting subcategorial conversion of other perception predicates (e.g. hear, whiff, bite) as well as other types of internal constraint making reference to the internal semantic configuration of the templates. The subcategorial conversion process is, however, not necessary for all perception predicates, as has been shown in the previous discussion. Many perception verbs have a semantically transitive nature (e.g. handle, smell, taste), although transitivity in the domain of perception is different from 
transitivity in other semantic domains. The actions expressed by perception predicates do not affect the object directly, but rather denote how the object is experienced perceptually by the subject. The use of these predicates is only possible because they are seen as prototypically transitive thanks to the effectual action metaphor whereby perception is conceptualized as instigated motion. However, the caused-motion interpretation cannot be attributed to the metaphorical mapping. Rather, it arises from the coercion imposed by the inherent semantics of the construction (Michaelis, 2003). By virtue of the metaphor, the meaning of perception verbs conforms to the meaning of the construction. In this respect, metaphor reveals itself as an explanatorily adequate tool to study the cognitive motivation and semantic constraints that allow the fusion of perceptual activities into the caused-motion construction.

\section{CONCLUDING REMARKS}

This article is a case study on how the set of constraints put forward by the LCM allows for the subsumption of perception predicates into the caused-motion construction. It has been argued that the incompatibility of this lexical class with the construction can be resolved through the application of high-level metaphoric operations that coerce verbal predicates to be integrated into the construction. This analysis has dealt with the idiosyncrasies of diverse realizations of the construction with perception predicates based on the interplay between the semantic properties of the verbs and the argument structure of the construction. The fusion of perception predicates into the construction has been shown as licensed by both internal and external constraints. Internal constraints operate by allowing verbs to modify their internal structure. For the caused-motion construction, predicate-argument conditioning has proved to coerce predicates into their configuration in terms of argument addition. With regard to the external constraints that are operative in the process, metaphor has been evidenced to underlie the conceptualization that permits the incorporation of perception into the caused-motion domain. The type of metaphor that applies in this case has an effectual action as the source domain and has been postulated within the LCM as motivating a number of grammatical conversions and conversion processes. This metaphor allows us to see a perceptual activity like tasting (i.e. one that has a psychological impact) as an effectual action (i.e. one with physical motion). Postulating this metaphor permits to derive meaning implications related to the balance between perception and effect, on the one hand, and between explicit and implicit motion, on the other. The results of the analysis providence evidence in favor of considering metaphorical conceptualization as a constraint in the fusion of verbs belonging to different lexical classes into the caused-motion construction. Further research should be carried out to determine in what way or to what extent similar external constraints developed by the LCM 
are active in the incorporation of perception predicates into different argument structure constructions of the kind postulated by Goldberg.

\section{ACKNOWLEDGEMENTS}

I would like to thank Dr. Francisco J. Ruiz de Mendoza for invaluable comments on earlier drafts of this paper. I would also like to thank Dr. Annalissa Baicchi for her suggestions and help. Any remaining errors are of course my own. Financial support for this research has been provided by the Spanish Ministry of Science and Competitiveness, grant number FFI2010 17610/FILO. This research is also associated with the Lexicom research group (www.lexicom.es).

\section{NOTES}

1. To get background on the caused-motion construction, it will be useful to review Jackendoff's (1990) and Levin and Rappaport Hovav's (1995) work.

2. For further updated information of the LCM, I refer the reader to the group research webpage: www.lexicom.es.

3. It is further argued that the lexical adaptation of predicates to constructional requirements is a consequence of the Override Principle (Michaelis, 2003), according to which the meaning of a lexical item conforms to the meaning of the structure with which it fuses. Thus, the verb laugh needs to be re-construed as a causative accomplishment predicate in order to participate in the caused-motion construction. The conversion is possible to the metaphorical interpretation of the verb.

4. In Goldberg's approach, the caused motion construction is considered a subtype of the resultative construction since both denote a change in the postverbal element. Within the LCM, it is claimed that the caused-motion construction is a family of the resultative family according to a metaphoric mapping which conflates destination with goals of action (see Ruiz de Mendoza and Luzondo, 2011). For this reason, Peña (2009) has argued in favor of a cognitive continuum between the caused-motion and the resultative constructions to account for the resultative meaning expressed through the figurative use of the caused-motion construction (e.g. He hammered the metal flat).

5. In the LCM, polysemy links are regarded as the side effect of the interaction possibilities between lexical and constructional configurations. The verb order, which is unrelated to motion, can take part in the caused-motion construction provided that it is compatible with or licensable with it by obeying internal and external constraints.

6. The term fusion was first introduced by Jakendoff (1990) to designate the combination of semantic constraints within a lexical entry. In the Goldbergian approach, the term captures the constraints regulating the integration of the participant roles of a verb and the argument roles in a construction. In the Lexical Constructional Model, the term makes reference to lexical constructional subsumption.

7. The reason for this irregularity is to be found in the different lexical-class ascription of each of the two verbs: whereas break is a change-of-state predicate, destroy codes cessation of existence, which prevents it from taking part into the inchoative construction (see Mairal and Ruiz de Mendoza, 2009; Ruiz de Mendoza and Peña, 2008).

8. Two different levels of description should be considered in order to understand the role of metaphor and metonymy in grammar. Ruiz de Mendoza (2007) has addressed this issue distinguishing between low and high description levels. The former are non-generic levels of conceptual representation created by making well-entrenched links between the elements of our encyclopedic knowledge store. Examples like Nixon bombed Hanoi illustrates a low-level metonymy (RULER FOR ARMY) in which both the source and the target domains constitute nongeneric cognitive models. High levels of description are created by deriving structure common to 
multiple low-level models (e.g. the notions of 'action' 'perception' and 'result'). The utterance There is too much chair in this room is a clear case of a high-level metonymy (OBJECT FOR MATERIAL) making use of generic cognitive models.

9. The examples analyzed have been extracted from Google. The choice of this source was dictated by the fact that it contains real chunks of language that provide a realistic picture of present-day usage.

10. Example drawn from: http://www.archive.org/stream/selectedpoemsofj00drin (accessed on August 27, 2012).

11. Example drawn from: http://caitlinwu.wordpress.com/2011/04/ (accessed on August 27, 2012).

12. Example drawn from: http://www.shortstories4free.com/18.html (accessed on August 27, 2012).

13. Example drawn from: books.google.es/books?isbn=0373527276 (accessed on August 27, 2012).

14. Example drawn from: http://www.preservearticles.com/201012291904/interesting-story-ontiger.html (accessed on August 27, 2012).

15. Example drawn from: books.google.es/books?isbn=0330503693 (accessed on August 27, 2012).

16. Example drawn from: http://www.spanishdict.com/translate/manhandled (accessed on August 27, 2012).

17. Example drawn from: http://es.scribd.com/doc/28193796/Keith-Laumer-Future-Imperfect (accessed on August 27, 2012).

18. Example drawn from: http://www.spcnet.tv/forums/showthread.php?27935-Ping-Zong-Xia-YingLu-The-Wanderer-chronicles/page6 (accessed on August 27, 2012).

19. Example drawn from: http://talkaboutmarriage.com/mens-clubhouse/16296-my-wife-kicked-meout-house.html (accessed on August 27, 2012).

20. Example drawn from: http://www.justia.com/criminal/docs/uniform-crime-reporting-handbook/ (accessed on August 27, 2012).

21. Example drawn from: http://answers.yahoo.com/question/index?qid=20080703080136AAXOVJv (accessed on August 27, 2012).

22. Example drawn from: http://www.twitwheel.com/sorry_im_bIZZY (accessed on August 27, 2012).

23. Example drawn from: http://www.storysite.org/story/ticklesandtreats 03.html (accessed on August 27, 2012).

24. Example drawn from: http://elliebloo.com/2009/11/27/ (accessed on August 27, 2012).

25. Example drawn from: http://www.youtube.com/all_comments?v=qkLjIiDD0ao (accessed on August 27, 2012).

26. Example drawn from: http://carolynpeeler.typepad.com/cut_n_paste/2006/10/index.html (accessed on August 27, 2012).

27. Example drawn from: http://www.fanfiction.net/s/5618549/1/Until_We_Meet_Again (accessed on August 27, 2012).

28. Example drawn from: http://forums.sidhe.co.nz/printthread.php?t=10367\&pp=20\&page=884 (accessed on August 27, 2012).

29. Example drawn from: http://www.fanfiction.net/s/8273486/2/Secondhand_Serenade (accessed on August 27, 2012).

30. Example drawn from: books.google.es/books?isbn=1406813613 (accessed on August 27, 2012).

31. Example drawn from: http://www.cosmopolitan.com/advice/ (accessed on August 27, 2012).

32. Example drawn from: http://es.scribd.com/doc/22404822/Treasure-Island (accessed on August 27, 2012).

33. Example drawn from: http://www.theaustralian.com.au/archive/travel-old/lessons-from-themasters/story-fn302659-1225952708982 (accessed on August 27, 2012).

34. Example drawn from: http://forums.presonus.com/posts/list/22436.page (accessed on August 27, 2012).

35. Example drawn from: books.google.es/books?isbn=9027223815 (accessed on August 27, 2012).

36. Example drawn from: http://askmagazine.nasa.gov/issues/29/29i_interview.html (accessed on August 27, 2012).

37. Example drawn from: http://www.fanfiction.net/s/7410749/1/Lemony_Tarts (accessed on August 27, 2012).

(C) Servicio de Publicaciones. Universidad de Murcia. All rights reserved. IJES, vol. 13 (1), 2013, pp. 89-110 Print ISSN: 1578-7044; Online ISSN: 1989-6131 
38. Example drawn from: http://www.thehighroad.org/archive/index.php/t-67844.html (accessed on August 27, 2012).

39. Example drawn from: http://dailyuw.com/news/2009/jul/15/editorial-cartoon-and-rants-and-raves/ (accessed on August 27, 2012).

40. Example drawn from: http://www.thefreelibrary.com/FLAT+SHARE+HELL.-a060639523 (accessed on August 27, 2012).

41. Example drawn from: books.google.es/books?isbn=1434991504 (accessed on August 27, 2012).

42. Example drawn from: books.google.es/books?isbn=9027223815 (accessed on August 27, 2012).

43. Example drawn from: http://orient.bowdoin.edu/orient/article.php (accessed on August 27, 2012).

44. Example drawn from: http://www.examiner.com/article/craft-beer-syzygy-the-conejo-valleyladyface-ales-part-three (accessed on August 27, 2012).

45. Example drawn from: http://news.priyo.com/national (accessed on August 27, 2012).

46. Example drawn from: swimatyourownrisk.com/category/shark-attacks/ (accessed on August 27, 2012).

47. Example drawn from: books.google.es/books?isbn=1408812002 (accessed on August 27, 2012).

48. Example drawn from: http://www.circleofmoms.com/search/pockets/30 (accessed on August 27, 2012).

49. See Ruiz de Mendoza and Mairal's (2007) treatment of metaphors with an effectual action in the source domain and how they constrain the interaction possibilities between verbal predicates and argument structure constructions.

\section{REFERENCES}

Baicchi, A. (2012). Metaphoric motivation in grammatical structure. The case of the caused-motion construction from the perspective of the Lexical-Constructional Model. In G. Radden, K.-U. Panther and P. Koch (Eds.), Motivation in Lexicon, Grammar, and Discourse. Amsterdam/ Philadelphia, John Benjamins. In press.

Croft, W.A. (2001). Radical Construction Grammar. Oxford: Oxford University Press.

Dik, S.C. (1989). The Theory of Functional Grammar. The Structure of the Clause. Berlin: Mouton de Gruyter.

Dik, S.C. (1997). The Theory of Functional Grammar. Complex and Derived Constructions. Berlin: Mouton de Gruyter.

Faber, P.B. \& Mairal, R. 1999. Constructing a Lexicon of English Verbs. Berlin/New York: Mouton de Gruyter.

Fillmore, C.J. (1968). The case for case. In E. Bach and R.T. Harms (Eds.), Universals in Linguistic theory (pp. 1-88). New York: Holt, Rinehart and Winston.

Goldberg, A.E. (1995). Constructions: A Construction Grammar Approach to Argument Structure. Chicago: University Press.

Goldberg, A.E. (2006). Constructions at Work: The Nature of Generalization in Language. Oxford: Oxford University Press.

Jackendoff, R. (1990). Semantic Structures. Cambridge: MIT Press.

Kay, P. \& Fillmore, C.J. (1999). Grammatical constructions and linguistic generalizations: The What's $\mathrm{X}$ Doing Y construction. Language 75, 1-33.

Kövecses, Z. and Radden, G. (1998). Metonymy: Developing a cognitive linguistic view. Cognitive Linguistics, 9, 37-77.

Lakoff, G. (1987). Women, Fire and Dangerous Things. Chicago: Chicago University Press.

Lakoff, G. (1993). The contemporary Theory of Metaphor. In A. Ortony (Ed.), Metaphor and Thought (pp. 202-251). Cambridge: Cambridge University Press.

Lakoff, G. \& Johnson, M. (1980). Metaphors We Live By. New York: Basic Books.

Langacker, R.W. (1991). Foundations of Cognitive Grammar. Descriptive Application. Stanford: Stanford University Press. 
Langacker, R.W. (2005). Construction Grammars: Cognitive, Radical and less so. In F.J. Ruiz de Mendoza and M.S. Peña (Eds.), Cognitive Linguistics: Internal dynamics and interdisciplinary interaction (pp. 101-159). Berlin: Mouton de Gruyter.

Levin, B. (1993). English Verb Classes and Alternations. Chicago: University of Chicago Press.

Levin, B. and Rappaport Hovav, M. (1995). Unaccusativity: At the Syntax-lexical Semantics Interface. Cambridge: MIT Press.

Luzondo, A. (2007). Semantic constraints on the caused-motion construction. Epos, 23, 167-180.

Michaelis, L. (2003). Word meaning, sentence meaning, and syntactic meaning. In H. Cuykens, R. Dirven and J.R. Taylor (Eds.), Cognitive Approaches to Lexical Semantics (pp. 93-122). Berlin/New York: Mouton de Gruyter.

Panther, K.-U. \& Thornburg, L. (2000). The EFFECT FOR CAUSE metonymy in English grammar. In A. Barcelona (Ed.), Metaphor and Metonymy at the Crossroads (215- 232). Berlin/New York: Mouton de Gruyter.

Peña, M.S. (2009). Constraints on subsumption in the caused-motion construction. Language Sciences, 31, 740-765.

Peña, M.S. \& Ruiz de Mendoza, F.J. (2009). The metonymic and metaphoric grounding of two imageschema transformations. In G. Panther, L. Thornburg and A. Barcelona (Eds.), Metonymy and Metaphor in Grammar (pp. 339-361). Amsterdam/Philadelphia: John Benjamins.

Ruiz de Mendoza, F.J. (2007). High level cognitive models: In search of a unified framework for inferential and grammatical behavior.” In K. Kosecki (Ed.), Perspectives on Metonymy (pp. 1130). Frankfurt/Main: Peter Lang.

Ruiz de Mendoza, F.J. (2011). Metonymy and cognitive operations. In R. Benczes, A. Barcelona and F.J. Ruiz de Mendoza (Eds.), Defining Metonymy in Cognitive Linguistics: Towards a Consensus View (pp. 103-124). Amsterdam/Philadelphia: John Benjamins.

Ruiz de Mendoza, F.J. \& Galera, A. (2012). Cognitive models and cognitive operations: Levels of representation and explanatory adequacy. Unpublished manuscript. University of La Rioja.

Ruiz de Mendoza, F.J. \& F. Gonzálvez. (2011). Illocutionary meaning revisited: Subjective-transitive constructions in the Lexical Constructional Model. In P. Stalmaszczyk (Ed.), Turning Points in the Philosophy of Language and Linguistics. (pp. 65-77). Frankfurt/Main: Peter Lang.

Ruiz de Mendoza, F.J. \& Luzondo, A. (2011). Lexical-constructional subsumption in resultative constructions in English. In M. Brdar, M. Zic Fuchs, I. Raffaelli, M.-M. Stanojevic and N. Tudjman Vukovic (Eds.), Cognitive Linguistics. Between Universality and Variation (pp. 117136). Cambridge: Cambridge University Press.

Ruiz de Mendoza, F.J. \& Mairal, R. (2008). High-level metaphor and metonymy in meaning construction. In G. Radden, K.M. Köpcke, T. Berg and P. Siemund (Eds.), Aspects of Meaning Construction in Lexicon and Grammar (pp. 33-49). Amsterdam/Philadelphia: John Benjamins.

Ruiz de Mendoza, F.J. \& Mairal, R. (2008). Levels of description and constraining factors in meaning construction: An introduction to the Lexical Constructional Model. Folia Linguistica, 42, 355400.

Ruiz de Mendoza, F.J. \& Mairal, R. (2011). Constraints on syntactic alternation: Lexicalconstructional subsumption in the Lexical-Constructional Model. In P. Guerrero (Ed.), Morphosyntactic Alternations in English. Functional and Cognitive Perspectives (pp. 62-82). London/Oakville: CT Equinox.

Ruiz de Mendoza, F.J. \& Peña, M.S. (2008). Grammatical metonymy within the 'action' frame in English and Spanish. In M.Á. Gómez-González, L. Mackenzie and E. González-Álvarez (Eds.), Current Trends in Contrastive Linguistics: Functional and Cognitive Perspectives (251-280). Amsterdam/Philadelphia: John Benjamins.

Ruiz de Mendoza, F.J. \& Pérez, L. (2001) Metonymy and the grammar: motivation, constraints and interaction. Language and Communication, 21(4), 321-357.

Van Valin, R.D. 2005. The Syntax-Semantics-Pragmatics Interface: An Introduction to Role and Reference Grammar. Cambridge: Cambridge University Press.

Van Valin, R.D. \& LaPolla, J.R. (1997). Syntax, Structure, Meaning and Function. Cambridge: Cambridge University Press. 